\title{
Bridging Social Capital on Facebook as a Platform: A Case Study of Malaysian College Students
}

\author{
Hamedi M. Adnan ${ }^{1} \&$ Samira Rahimi Mavi ${ }^{1}$ \\ ${ }^{1}$ Department of Media Studies, University Malaya, Kuala Lumpur, Malaysia \\ Correspondence: Hamedi M. Adnan, Department of Media Studies, University Malaya, 50603 Kuala Lumpur, \\ Malaysia. Tel: 60-13-362-2010. E-mail: hamedi@um.edu.my; samira.rahimi.mavi@siswamail.um.edu.my
}

Received: May 17, 2014 Accepted: December 6, 2014 Online Published: May 15, 2015

doi:10.5539/ass.v11n15p1 URL: http://dx.doi.org/10.5539/ass.v11n15p1

\begin{abstract}
Bridging social capital is a significant predictor in national solidarity. Although Malaysia is known as a fairly successful multi-ethnic country, it still divides along ethnic and religious lines. The underlying question is whether Social networking sites like Facebook, carry out contributory agent reinforcing bridging social capital among different ethnics. The current research will be functional in filling up these gaps by defining the role of Facebook in individuals' bridging social capital among Malaysian college students. An online questionnaire survey used in this study aimed to evaluate the association between the intensity of using Facebook, bridging social capital and different ethnics and age groups. In conclusion, the amount of use of Facebook is an insignificant factor affecting online bridging social capital among Malaysian undergraduates.
\end{abstract}

Keywords: Facebook, social capital, online bridging, college students

\section{Introduction}

Much of the debate over social capital and online social networking sites is concerning the function of social networking sites in shaping social capital. Many of previous studies have attempted to uncover the role of the amount of media use in maintaining social relationships in communities, while some of which focused on the negative effects of media on social capital. They mostly argued that media use decreased sociability and face-to-face communications and loosened social networks (Putnam, 2000; Nie \& Erbring, 2000). Putnam, in his famous book Bowling Alone (2000), pointed out that social capital had decreased in America in the post-war years mainly because of the development of technology and media. He argued that younger generations are less connected to and also less engaged in social activities than the past, particularly since the media has turned into a major part of their leisure activities (Putnam, 2000).

The popularity of social media is rapidly growing among Malaysian youth. Today, the use of digital media, online social networking, mobile media, video and photo uploading, and many other interactive activities are getting more and more common and accessible. It is thought that online communities improve relations between individuals and strengthen social networks (Wellman et al., 1996; Wellman et al., 2001). The emergence social networking sites (SNSs) flourished the theory that online community yielding social outcomes, bonding existing ties and bridging acquaintances (Burke, Marlow, \& Lento, 2010; Ellison, Steinfield, \& Lampe, 2007; Steinfield, DiMicco, \& Ellison, 2009; Valenzuela, Park, \& Kee, 2009). The growing evidence from previous studies indicated that online communities provide more benefit bridging acquaintances than bonding close ties. Many advantages derived from bridging social capital within social networks determined by weak ties, such as cultural exposure and felling part of bigger community (Putnam, 1995; Woolcock \& Narayan , 2000; Donath \& Boyd, 2004).

Increasing bridging capital, trust and sense of community is boosted parallelly; particularly it is significant in communities having diversity such as Malaysia which dealing with racial, ethnic and religious issues. Studies suggest that communities with ethnic and racial diversity often come up with a lower level of social capital than homogeneous communities (Zak \& Knack, 2001). Although, Malaysia is known as a fairly successful multi-ethnic country that can still be used as a model for a country that has effectively managed its ethnic relations, there is no doubt that Malaysians are still divided along ethnic and religious lines. However incidences of outward hostility between the different ethnic groups have been on the decline (Farouk \& Mohammad Zaini, 2007 
However, the concept of social capital has been arisen from western literature and majority of studies has been conducted in western context in which the ethnical gaps do not figure prominently in the social structure (Farouk \& Mohammad Zaini, 2007). In recent years, Malaysian scholars have become more concerned with the role of online communities in social capital. There are studies conducted in Malaysia in which online interaction and social capital are central keys (Mohd Yousef \& Faizal Hashim, 2014; Wan Jafar, 2014). However, taking the idea that SNSs are social in their essence and connect wide spread networks of contacts, this study in line with optimistic views rises the underlying question whether SNSs like Facebook as mediating factors, carry out contributory agent reinforcing bridging social capital among different ethnics groups. The current research will be functional in filling up this gap by defining the role of Facebook in individuals' bridging social capital among Malaysian college students.

\section{Background of Research}

\subsection{Social Capital}

The term of social capital has been a controversial and slippery term (William, 2006). Most of the definitions of social capital are based on the networks of relationships between individuals and groups; Coleman, (1998) defined social capital as the resources available that individuals benefit their membership in community network. (Putnam (2000) in his book Bowling Alone defined social capital as connections among individuals and the social networks and the norms of reciprocity and trustworthiness derived from them. Furthermore, there has been confusion in the literature about whether social capital is a cause or an effect (William, 2006). William (2006) cited through Foley \& Edwards (1997) that some researchers assume the social groups and networks yield positive outcomes like emotional support and ability to mobilize others whereas other researchers thought it the outcomes themselves. In William's (2006) view, social capital is identified as outcomes, but Putnam's (2000) approach rests on the idea that social capital is both network and outcome. In the present study, social capital is measured as outcome and following William (2006), we consider network as the causal agents and moderators.

\subsection{Bridging Social Capital}

Putnam (2000) drew a distinction between bridging and bonding social capital. These two types of social capitals are related but not equivalent (William, 2006). To make a distinction between bridging and bonding capitals, according to Putnam, bonding social capital is produced by a kind of connections among those in more strongly tied and homogeneous communities such as family and close friends (Putnam, 2000). But bridging social capital is more inclusive and involves ties between more heterogeneous networks of relationships. The first one provides emotional support, but the second one usually contributes to the social and political interaction (Zhang et al., 2009). Furthermore, bridging social capital arises from the connections between diverse networks. The relationships formed here are often loosening, because they are generated as a result of the weak ties between the individuals from dissimilar backgrounds (Granovetter, 1973; Putnam, 2000) like those between far acquaintances or different ethnic groups.

The relationships between weak ties are usually less permanent and mainly tentative with less emotional support. These types of relationships lack in depth, although they are broaden in breadth. (William, 2006). For example, Granovetter, 1973, 1974) found that job seekers with broaden weak network of relationships are more successful in finding a job than those with strongest relationship and friendship. In fact, these job seekers have gained benefit from their bridging social capital that comes from their weak-tie network. However, what this line of argument calls into question is that how do these not deep relationships in online community yield positive outcomes. Studies suggest that, online communities enable members to keep up with the others for having richer and more diverse resources (Son \& Lin, 2008). William (2006b) stipulated that weak social ties include expanding social horizons or world views, opening up opportunities for new information resources and allowing connections among groups or civic organizations which are otherwise disconnected (Williams, 2006b). This is because the members of weak-tied networks have a better opportunity to connect with external assets and information resources. Furthermore, bridging ties makes the information exchange easy among the groups with different backgrounds. On top of that, weak ties expedite the circulation of ideas among the groups. In brief, these ties are essential in transforming a community into a whole, as well as organizing the collective actions of the community (Kavanaugh et al., 2005). However, online communities and internet tools are inherently handy gathering weak ties of networks from different background, either politically or in terms of ethnicity, religion, gender, and age line.

\subsection{Online Social Networking and Social Capital}

Online social networking can affect social capital in many different ways. For example, a group to which individuals join based on the common interests can give the users this opportunity to co-ordinate collective 
actions. Habitual interactions between online social networking users enable them to develop trust and norms of reciprocity which are both key elements in the community life. Online news updates also facilitate preserving the contact with the others and learning more about the world around (Valenzuela, Park, \& Kee, 2009). The theme of these studies, i.e. that main purpose of using online social networking, is continuing interaction with preexisting connections. Boosting online social networking stimulated numerous studies to examine whether social network sites enhance social capital. These studies mainly focus on the ability of these sites to enhance a sense of community and try to understand whether bridging and bonding social capital are built through these online social networking websites (Boyd \& Ellison, 2007; Lampe, Ellison, \& Steinfield, 2006).

The majority of previous studies conducted, suggest that perceived amounts of bridging social capital associate with highly Facebook use (Ellison, Steinfield, \& Lampe, 2007; Ellison, Lampe, \& Steinfield, 2009; Steinfield, Ellison, \& Lampe, 2008; Steinfield, DiMicco, \& Ellison, 2009). These studies primarily indicated that there exists a stronger correlation of bridging social capital made through Facebook use. This suggests that greatly engaged Facebook users are using Facebook to form relationships that might otherwise remain fleeting (Ellison, Steinfield, \& Lampe, 2007. The mecanism of SNSs is that by generating latent ties conectivity among group members put function as technical means for activating weak ties (Haythornthwaite, 2005, p. 135). These latent tie are potentiall social networks ties that have yet not activated socially (Haythornthwaite, 2005). Facebook provides users to capitalize on weak ties, like friending with friends of friend. It is also rather powerful to transform the latent ties into weak ties. For example finding some one in a discussion groups with mutual areas of interests.

Facebook has a mechanism through which provide users with easier method to reach information. For example, it enables members to benefit information through weak and latent ties and the site itself offers a mechanism for joining discussion groups and announcing and social events. Howere the weak ties will provide additional information and opportunities (Donath \& boyd, 2004; Ellison, Steinfield, \& Lampe, 2007; Zhang et al., 2009).

A comprehensive study was done in 2011 by Ellison et al. (2011). It investigated the impact of Facebook enabled communication practices. Ellison et al. (2011) in their study revealed that Facebook is not likely to provide social communication practices. The study was done with a representative of Facebook users among the youths. Their study also found out that communication practices on the site has a direct impact on social capital outcome. The results of the study revealed and underscored the importance of examining, not just the social website in use but what individuals do in relation to activities done with the provided sites (Ellison, Steinfield, \& Lampe, 2011).

In recent years, some scholars in Malaysia have studied online community interaction. Some of which have focused on online local community. A study conducted by Wan Jafar (2014) examined six online local communities exclusively used by Malays, Chinese and Indian users, capturing whether online social networking affects the forms of social capital and social integration. This study indicated that there was a great potential for enhancing social networks across all members. Another study conducted by Mohd Yousef \& Faizal Hashim (2014) found that norms, togetherness, sociability, connections, and volunteerism as important factors that build up social capital among virtual community members in Malaysia. Based on the brief review of the social capital and online social networking, this research aims to address the issue by evaluating the association between Facebook use and online bridging social capital.

This study is based on the following research questions and hypotheses.

Q1. Are there significant associations in intensity use of Facebook, demographics variables, such as by gender, years in college, ethnics and residential status and online bridging social capital?

H1. Intensity use of Facebook positively predicts online bridging among Malaysian college students.

H2. There are major differences in intensity use of Facebook, online bridging with different purposes of Facebook use like "keeping in touch with current contacts" and "making new friends"

\section{Method}

To obtain the target of this research, an online questionnaire was designed and sent to undergraduate students through students official email that provided by university (SISWA mail). The questionnaire was launched between October 1, 2013 and November 1, 2013. Total number of 824 respondents answered to the questions. The response rate was approximately $61.7 \%$. The sample population was composed of both male and female students who ranged within an age group of 18-25. 


\subsection{Measures}

Demographics Variable: The summary of statistics of demographics describes the composition of the sample that was used in the study. The study was composed of both male and female users. Their ages varied between $18-25$ years with the average of $22.17(\mathrm{SD}=1.45)$ years. This is an important sample as it shows the target age users of the Facebook as a social media. The female formed the largest proportion of 59.3\% while men $41.2 \%$. All races were included in the study to make the results complete, reliable and comprehensive. However Malays had the highest participation ( $47 \%$ ). The table also utilizes the sample residential to show. It was composed of both students residing in school $(\mathrm{M}=1.55, \mathrm{SD}=.532)$ and those who had accommodation outside the university.

Intensity of Facebook use and pattern of Facebook use: The popular approach measuring intensity of Facebook use developed by Ellison et al., (2007) in which, in spite of being measure the amount of time spent on Facebook on a daily basis, and the size of network of friends, students' Facebook emotional involvement also is measured. To do so, the current study follows the same approach (Table 1).

In order to identify the pattern of Facebook use by invoking measurement proposed by Ellison et al., (2007), we adopted two scales capturing that, Malaysian undergraduates if use Facebook to stay in touch with people they know or to meet new friends (Table 1).

Table 1. Intensity of Facebook use and pattern of Facebook use

\begin{tabular}{lll}
\hline & Mean & Std. Deviation \\
\hline How much time do you log on to Facebook? & 5.10 & 1.408 \\
1=0 hour, $2=$ less than 10 min, $3=$ up to 30 min, $4=30$ min up to 1 hour & & \\
5=1 to 2 hours, $6=2$ to 3 hours, $7=$ more than 3 hours & 6.43 & 2.345 \\
How many total Facebook friends? & & \\
1=less than $10,2=10-49,3=50-99,4=100-149,5=150-199$, & \\
6=200-249, 7=250-299, $8=300-399,9=400$ or more & & \\
& 2.85 & 2.12 \\
I feel I am part of Facebook community & 2.27 & 1.180 \\
I feel out of touch when I haven't logged on to Facebook for a while & 2.14 & 1.129 \\
I would be sorry if Facebook shout down & 2.00 & 1.113 \\
Facebook has become part of my everyday routine & 2.27 & 1.126 \\
Facebook is part of my every day activity & 2.11 & 1.117 \\
I am proud to tell people I'm on Facebook & & \\
& 4.32 & .984 \\
I use Facebook to stay in touch with people I know & 3.57 & 1.246 \\
I use Facebook to meet new people & & \\
\hline
\end{tabular}

\subsection{Dependent Variable}

Bridging social capital: Bridging capital was measured as dependent variables laid down based on the characteristics of Williams' (2006) study which includes six items (Table 2). To measure bridging social capital, we change a few minor words. The items are as following: "Interacting with people on Facebook makes me feel part of a large community" (note: we replaced Facebook instead of online in all six items). "Interacting with people on Facebook makes me interested what people unlike me or thinking". "Talking with people on Facebook makes me curious about other places in the world". "Interacting with people on Facebook reminds me that everyone in the world is connected". "Interacting with people online makes me want to try new things". "I am willing to spend time to support general Facebook community activities". To measure Facebook bridging social capital a 5-point Likert scale was used as a response format ranging from strongly disagree (1) to strongly agree (5).

\section{Results}

Table 1 shows the intensity of the use of Facebook among the sample. Among the respondents $(\mathrm{M}=5.10, \mathrm{SD}=$ 1.408) affirmed that they spent 1-2 hours daily on Facebook. According to this table the average number of Facebook friends ranges from 200-299 $(\mathrm{M}=6.43)$. Participants reported they feel they are part of Facebook community (Mean=2.85) and Facebook is part of their everyday activities (Mea=2.27). Most students reported 
they use Facebook primarily to stay in touch with people they know $(\mathrm{Mea}=4.32)$ and then to meet new people (Mean=3.57).

To obtain the extent of Facebook bridging social capital (Table 2), we conducted a component factor analysis with Varimax rotation. The factor analysis loaded into six factors and the total variance was 59.78. Each factor had an eigenvalue of at least 1 . The absolute value for factor loading was measured at .30. The results of factor analysis Facebook bridging suggests that the respondents gained a higher level of bridging for "interacting online with people making them feel part of a large community" (Variance $=30.1, \alpha=.89$ ). Results also show that that respondents could benefit from "Interacting online with people make me interested what people unlike me or thinking" (Variance $=11.3, \alpha=.88$ ). The table illustrates that respondents agreed that "Interacting with people online reminds me that everyone in the world is connected" (variance $=7.04, \alpha=.88$ ). Respondents also reported that "Interacting with people online makes me want to try new things" (variance $=5.61, \alpha=.87$ ). Our result also found that students believed that "Talking with people online make me curious about other places in the world" (variance $=3.63, \alpha=.86$ ). Finally, the last factor loaded into item "I am willing to spend time to support general online community activities" (variance $=2.11, \alpha=.86$ ).

Table 2. Factor analysis of online bridging (component matrix)

\begin{tabular}{lccc}
\hline $\begin{array}{l}\text { Online bridging (chronbach's alpha }=.86-.89 \text { ) } \\
\text { Total variance= 59.78 }\end{array}$ & Mean & Std. & $\begin{array}{c}\text { Factor } \\
\text { loading }\end{array}$ \\
\hline $\begin{array}{l}\text { Interacting with people on Facebook makes me feel part of a large community } \\
\text { Interacting with people on Facebook makes me interested what people unlike }\end{array}$ & 3.84 & 1.163 & .786 \\
me or thinking & 1.153 & .785 \\
$\begin{array}{l}\text { Interacting with people on Facebook reminds me that everyone in the world is } \\
\text { connected }\end{array}$ & 3.85 & 1.075 & .784 \\
Talking with people on Facebook makes me curious about other places in the & 3.87 & 1.068 & .760 \\
world & 3.76 & 1.066 & .774 \\
Interacting with people on Facebook makes me want to try new things & 3.67 & 1.81 & .749 \\
\hline
\end{tabular}

Q1. Are there a positive significant association in intensity use of Facebook, demographics variables, such as by gender, years in college, ethnics and residential status and online bridging social capital?

To answer Q1, we conducted regression equation (Table 1). Findings of this study showed a significant association between gender and online bridging. The results illustrates that R2 improved online birding only by gender $(\mathrm{Beta}=1.081, \mathrm{t}=2.66, \mathrm{P}=.008<0.05)$. This finding suggests that, foregoing intensity and other demographic factors, gender alone was significant determinant in online bridging which can affectively optimize network of weak ties. To compare the difference between mean scores, an independent T-test was conducted. Our findings detected that the difference in mean score was significant $(\mathrm{F}=2.51, \mathrm{P}=.005<0.05)$. We found that male students (Mean=23.35, $\mathrm{SD}=5.20$ ) could gain a higher level of online bridging social capital than female students $(\mathrm{M}=22.26, \mathrm{SD}=5.69)$.

H1. Intensity use of Facebook positively predicts online bridging among Malaysian college students.

To obtain the hypothesis of the current study, the regression equation inserted to elaborate the association between different aspects of Facebook (Table 3). The result of the regression analysis, contrary to what this study hypothesized shown that, intensity of Facebook use did not perform as a significant factor reinforcing online bridging (Beta=.002, $\mathrm{P}=>$. 878). Therefore, according to the table, it can be said that, this study failed to confirms the hypothesis for association between Facebook intensity usage and online birding, or in other words, online bridging capital either positively or negatively is not affected by intensity of Facebook use.

H2. There are major differences in intensity use of Facebook, online bridging with different purposes of Facebook use like "keeping in touch with current contacts" and "making new friends"

Conducting regression equation (Table 3), as we expected, we found that using Facebook for "Making new friends" positively predicted online bridging social capital (Beta $=.341, \mathrm{P}=.036<.05$ ). Facebook seems to allow Malaysian users to find new connections to increase their online bridging. However our analysis, did not find any relationship between using Facebook for "Keeping in touch with current contacts" and online bridging social capital. 
Table 3. Regression predicting, testing the hypothesis

\begin{tabular}{lccc}
\hline \multirow{2}{*}{ Independent variable } & \multicolumn{3}{c}{ Dependent variables } \\
\cline { 2 - 4 } Age & \multicolumn{3}{c}{ Online bridging } \\
\hline Gender & Beta & $\mathrm{t}$ & Sig. \\
Ethnic & .101 & 800 & .428 \\
Year in college & .1 .081 & 2.661 & $\mathbf{. 0 0 8}$ \\
Living statues & .286 & 1.072 & .284 \\
Intensity of Facebook use & .120 & .517 & .605 \\
I use Facebook Keeping in touch with my existing contact & -.498 & -1.134 & .257 \\
I use Facebook Making new friends & .002 & .154 & .878 \\
R2=.138 & -.058 & -.226 & .821 \\
\hline
\end{tabular}

\section{Discussion}

Basically, this study aimed at exploring significant relationship between intensity of Facebook and social capital among Malaysian undergraduate students. This study investigated whether intensity of Facebook use including the time spent daily on Facebook, the number of Facebook friends, and emotional involvement is related to configuration and preservation of bridging social capital level. In line with the findings of previous research (Ellison, Steinfield, \& Lampe, 2007; Liu, Shi, Liu, \& Sheng, 2013), we hypothesized that there would be positive relationships between them. But, contrary to our prediction, the findings of this study did not appear to be coupled with association between intensity of Facebook use and online bridging. Contrary to previous studies (e.g., Ellison, 2007; Min-Woo, D'Angelo, \& Douglas, 2013), these findings support the idea that heavy Facebook users neither positively nor negatively could predict Facebook birding social capital.

Although the current study did not find evidence that intensity of Facebook use predicts increased bridging Social capital, these findings should not be deduced as negatively. This study supports the idea that users' pattern of use is a far determining factor emerging social outcomes than the intensity of use. There are some possible explanations. First, it can be said that SNSs as a highly interactive communication tool has been providing users to interact throughout quite wide network. This feature of SNSs has led users to don't remain as a merely consumer; SNSs enable users producing contents, receiving and sending feedbacks and managing their interactions. Second, SNSs are recognized to offer users with multiple functions of use. For example, Facebook facilitated users to make use of interpersonal communication, group interaction, seeking for news and information, making new friends, uploading videos and sharing pictures and status. These capabilities have mainly caused users to make a purposive use of Facebook. Accordingly, this study suggests that the type of interaction is a more arguable issue for defining Facebook birding capital than the intensity of use, and this is in line with Shah, Kwak, \& Holbert (2001) who stated patterns of use may be a more profitable route to explore the effects of the Internet than gross hours of use. Future research should address what other interaction types influence social capital.

Our suggestion is even more sensible, especially when the findings show that using Facebook for meeting new people predicts online bridging. Even though most participants reported using Facebook to stay in touch with their existing contacts but the results of regression equation illustrated that those using Facebook to meet new people benefit from Facebook bridging capital. Bridging social capital is built through network of weak ties, like those between new acquaintances. Taking the intended purpose of SNSs is obviously connecting people to broader network, so it is convincing enough that meeting new people is as best practical approach broadening social network to get advantages of weak ties.

While, previous studies reported that ethnicity was a significant variable related to Facebook online bridging (Ellison et al., 2007), the results of this undergraduates' survey were not significant to predict association between different ethnic groups and bridging social capital over Facebook. However, this insignificant association reminds us again that mere online contact between different ethnic groups does not automatically boost online bridging; we can conclude that intensive use of Facebook is not as powerful as a mediating factor to dwarfed differential culture, religious and language barriers bridging different ethnic groups. Instead, gender interactions throughout Facebook seem to play a decisive role in increasing bridging social capital among 
Malaysian undergraduates. Inclusion of gender variable into regression test revealed that gender is significant enough to predict Facebook online bridging. Assessing the extent to which females or males in their mean related to online bridging, T-test identified that males and females differ in their mean. The result delineated that male students could gain higher mean namely they keep higher level of online bridging.

These results therefore led to a question: what is the essence of online social capital? The first interpretation is to view online social capital as a necessary community-building alternative to the traditional offline social capital-building activities. Resnick (2001) adopted this view and referred to online social capital as "socio-technical capital", simply meaning the "productive combinations of social relations and information and communication technology" (p. 648). The study argues that socio-technical capital is a subset of social capital and also an important subcategory due to its capability in capturing new technologies offering the users new opportunities.

As Gershuny (2002) argued that the Internet may be changing the nature of leisure activities, the same thing can be inferred from social networking sites on the nature of communication. Interestingly, instead of displacing leisure or communication, social networking sites now constitute a new communication activity that supplements communication among friends and acquaintances.

\section{Conclusion}

The survey conducted has tried to examine association between intensity use of Facebook and the online bridging social capital among Malaysian college students. The results of these Malaysian undergraduate students suggest Facebook as an online social networking tool potentially yielding to remarkable social outcomes. Students mainly reported having perceptible level of bridging social capital. Facebook seems to be succeeding increasing sense of community and linking Malaysian college students to the broader community. Facebook intensity use, however, does not appear to play significant role forming online bridging. This study suggests that gender interaction through Facebook is a more reliable agent to shape online bridging. In addition, our findings propose that even though most students reported to use Facebook to stay in touch with their current contacts but using Facebook to meet new people is significantly helps them to benefit of building online bridging. Therefore, this finding leads us to conclude that quality of interaction through Facebook is more significant factor than the quantity of interactions.

Although the result of this study revealed that intensity use of Facebook cannot be as a mediatory factor to linkage between different ethnicity groups. But still the importance of this study is the identification of the effects of the Internet-related activities in a society with ethnicity and culture diversity. The importance of the concept of social capital in the societies with ethnic and cultural diversity is more than in uniform societies, because it has proved to be effective in establishing national solidarity. Therefore, bridging social capital produced by the linkage between dissimilar ties is essential.

In conclusion, having the result of this study in mind, we can state that going online has become an inseparable part of the people's life. Although there is still far to say Facebook may broaden weak ties among different ethnic groups. But it is still promising that different type of interactions may cause positive outcomes gathering different ethnicities together. However future research should identified which specific online interactions reinforcing online bridging among different ethnicity groups.

\section{References}

Boyd, M. D., \& Ellison, N. B. (2007). Social network sites: Definition, history, and scholarship. Journal of Computer-Mediated Communication, 13(1).

Burke, M., Marlow, C., \& Lento, T. (2010). Social network activity and social well-being. ACM CHI 2010: Conference on Human Factors in Computing Systems, 1909-1912.

Coleman, J. S. (1998). Social capital in the creation of human capital. American Journal of Sociology, 94, 95-120.

Donath, J., \& Boyd, D. (2004). Public displays of connection. BT Technology Journal, 22(4), 71. http://dx.doi.org/10.1023/B:BTTJ.0000047585.06264.cc

Ellison, N. B., Lampe, C., \& Steinfield, C. (2009). Social network sites and society: Current trends and future possibilities. Interactions, 16(1), 6-9.

Ellison, N., Steinfield, C., \& Lampe, C. (2007). The benefits of Facebook "Friends:" social capital and college students' use of online social network sites. Journal of Computer-Mediated Communication, 12(4), 1143-1168. 
Ellison, N., Steinfield, C., \& Lampe, C. (2011). Connection strategies: Social capital implications of Facebook-enabled communication practices. New Media \& Society, 13, 873-892.

Farouk, A., \& Zaini, M. (2007). State-induced social capital and ethnic integration: The Case of Rukun Tetangga in Penang. Universiti Sains Malaysia. Kajian Malaysia, 1, 41-60.

Ferlande, S. (203). The internet, social capital and local community (Ph.D. Thesis).

Gershuny, J. (2002). Web-Use and Net-Nerds: A Neo-Functionalist Analysis of the Impact of Information Technology in the Home. Colchester, UK: Institute for Social and Economic Research.

Granovetter, M. (1973). The strength of weak ties. The American Journal of Sociology, 78(6), 1360-1380.

Kavanaugh, A. L., Reese, D. D., Carroll, J. M., \& Rosson, M. B. (2005). Weak ties in networked communities. The Information Society, 21(2), 119-131.

Lampe, C., Ellison, N., \& Steinfield, C. (2006). A Face(book) in the crowd: Social searching vs. social browsing. In Proceedings of the 2006 20th Anniversary Conference on Computer-Supported Cooperative Work (CSCW 2006) (pp. 167-170). New York: ACM Press.

Liu, H., Shi, J., Liu, Y., \& Sheng, Z. (2013). The moderating role of attachment anxiety on social network site use intensitysity. Psychological Reports, 112, 252-265.

Min-Woo, K., D'Angelo , J., \& Douglas , M. (2013). Facebook use and social capital: To bond, to bridge, or to escape. Bulletin of Science, Technology \& Society, 33(1-2), 35-43. http://dx.doi.org/10.1177/0270467 613496767

Mohd Yousef, S. A., \& Faizal Hashim, K. M. (2014). Let's get together: Exploring the formation of social capital in a Malaysian virtual community. The Journal of Community Informatic, 10(1).

Nie, N. H., \& Erbring, L. (2000). Internet and Society: A Preliminary Report. Stanford, CA: Stanford Inst. Quant.

Putnam, R. (1995). Bowling alone: America's declining social capital. Journal of Democracy, 6, 65-78.

Putnam, R. (2000). Bowling Alone: The Collapse And Revival of American Community. New York: Simon \& Schuster.

Resnick, P. (2001). Beyond bowling together: Sociotechnical capital. In J. M. Carroll (Ed.), Human-computer interaction in the New Millenium (pp. 647-672). New York: Addison-Wesley.

Shah, D. V., Kwak, N., \& Holbert, R. L. (2001). "Connecting" and "disconnecting" with civic life: Patterns of Internet use and the productionof social capital. Political Communication, 18, 141-162. https://www.journalism.wisc.edu/ dshah/PC2001.pdf

Son, J., \& Lin, N. (2008). Social capital and civic action: A network-based approach. Social Science Research, 332. http://x.doi.org/10.1016/jssreserach.2006.12.004

Steinfield, C., DiMicco, J., \& Ellison, N. B. (2009). Bowling online: social networking and social capital within the organization. Proceedings of the Fourth International Conference on Communities and Technologies. ACM, University Park, pa, USA.

Steinfield, C., Ellison, N. B., \& Lampe, C. (2008). Social capital, self-esteem, and use of online social network sites: A longitudinal analysis. Journal of Applied Developmental Psychology, 29, 434-445. http://dx.doi.org/10.1016/j.appdev.2008.07.002

Valenzuela, S., Park, N., \& Kee, K. F. (2009). Is there social capital in a social network?:Facebook use and college students' life satisfaction, trust, and participation. Journal of Computer-Mediated Communication, $14,875-901$.

Wan Jafar, W. (2014). Exploring social capital in Malaysian on-line ethnic communities. A Multi Disciplinary Journal of Global Macro Trends, 3(2), 170-187.

Wellman, B., Quan Hasse, A., Witte, J., \& Hampton, K. (2001). Does the Internet increase, decrease or supplement social capital? Social network participation and community communication. American Behavioral Scientists, 45(3), 436-455. http://dx.doi.org/10.1177/00027640121957286

Wellman, B., Salaff, J., Dimitrova, D., Garton, L., Gulia, M., \& Haythornthwaite, C. (1996). Computer networks as social networks: Collaborative work, telework, and virtual community. Annual Review of Sociology, 22, 213-238. 
William, D. (2006). On and off the net: Scales for social capital in an online era. Journal of Computer-Mediated Communication, 11(2). http://dx.doi.org/10.1111/j.1083-6101.2006.00029.x

Woolcock, M., \& Narayan, D. (2000). Social Capital: Implications for Development Theory, Research, and Policy. Final version submitted to the World Bank Research Observer.

Zak, P. J., \& Knack, S. (2001). Trust and growth. Economic Journal CXI, 470, 291-321.

Zhang, W., Johnson, T. J., Seltzer, T., \& Bichard, S. L. (2009). The revolution will be networked the influence of social networking sites on political attitudes and behavior. Social Science Computer Review, 28(1), 75-92. http://dx.doi.org/10.1177/0894439309335162

\section{Copyrights}

Copyright for this article is retained by the author(s), with first publication rights granted to the journal.

This is an open-access article distributed under the terms and conditions of the Creative Commons Attribution license (http://creativecommons.org/licenses/by/3.0/). 